\title{
A Study on Spatial Distribution and Hierarchy of Chinese Jin Great Wall Defensive Settlements
}

\author{
Dan XIE \\ School of Architecture \& Art Design of Hebei University of Technolgy, Tian Jin, China
}

Xing ZHAO

School of Architecture of Tianjin Chengjian University, Tianjin, China

Yukun PANG

Department of Architectural Design,Tianjin Huahui Architectural Design \& Engineering CO.,LTD, Tian Jin, China

\begin{abstract}
Chinese Jin Great Wall Defensive Settlement, built earlier than Jin Boundary Moat, is an important component of the Jin Great Wall defensive system and is a hierarchical defensive system. It does not only have national characteristics but also have regional characteristics, but for years, the conservation of the Jin Great Wall defensive settlements has not been fully understood like that of boundary moats, which seriously restricts the value cognition and conservation planning of Jin Great Wall. This paper achieves the goal of expanding lineal cultural heritage resources and promoting the historical and cultural value through improving the past traditional ideas and technologies about Great Wall study and conservation, and provides a more comprehensive and powerful foundation for the integrated conservation principle and strategy of the Jin Great Wall.
\end{abstract}

KEYWORD: Defensive settlement; Jin Great Wall; spatial distribution; hierarchy

\section{PARTICULARITY OF GREAT JIN WALL CULTURAL HERITAGE AND URGENCY OF INTEGRATED CONSERVATION}

The Jin Great Wall defensive system is the material embodiment of specific military defense organizational system of Jin Dynasty with integrity and hierarchy, and contains important historical information of Jin Dynasty such as political change, military management, postal delivery and transportation system, foreign trade and exchange and military technologies. Compared to the great wall of the former dynasty, the Jin Great Wall defensive system is more integrated and systematic, and it is a product of recreation of the original great wall defensive system in a certain historical period according to the needs and objective conditions. The innovation and development of the Jin Great Wall plays a key role in the formation of the Great Wall Defensive System of Ming Dynasty.

In the past, the understanding and conservation of the "Great Wall Cultural Heritage" laid emphasis on the wall of Great Wall and important passes, but

Sponsor: Hebei Social Science Fundation of China (No. HB14SH029), National Natural Science Foundation of China (No. 51408183), Hebei Science and Technology Plan Project of China (No. 13276253). ignored the hierarchical defensive system of the Great Wall and the military settlements along the line. There are distinctive hierarchies and interdependent spatial relationships between the Great Wall body and military settlement and between the military settlements of different sizes. Clarifying the hierarchies and spatial relationships is the foundation to thoroughly understand the integrity of the Great Wall and the precondition of fully conserving the Great Wall cultural heritage. The Jin Great Wall military settlements have hierarchical characteristics, are of network distribution in space, combine staged defense and defense in-depth, and present a radial spatial structure. [1]

\section{FORMATION OF THE JIN GREAT WALL MILITARY SETTLEMENTS}

At the overall planning stage of the Jin Great Wall, the formation of military settlements and that of boundary moats are not synchronized. On the whole, the boundary moats were formed before the military settlements. However, as far as the layout of the military settlements is concerned, it experienced the process from point defense, to linear hierarchical defense and to planar hierarchical defense. In this process, the defense capability was constantly strengthened and the settlement hierarchy became clearer and clearer. 


\subsection{Point defense period}

The military settlement defense in this period was not "systematic". Principally, military fortresses were set up at the important defense sites for local defense, and there was no wing on the left side and right side for joint defense and no military fortresses in the rear for rear support. The fortresses at the important military sites administered in their own ways without any strategic connection. Such defense could not effectively resist the enemy's attack and had no sustainable fighting capability.

This period was mainly the great wall defensive system period with Shangjing Huining Prefecture as the defense center, and there were few military fortresses which were mostly used in cities of Liao Dynasty. After the analogy of fortresses in this period, it is found that the defense capability of fortresses was low; the fortress perimeter was small; the wall was low and there were no such defense installations as horse face, barbican and moat.

\subsection{Linear hierarchical defense period}

The military settlement defense in this period was preliminarily systematic, changing to linear hierarchical defense from point defense and to multilayer military fortress defense from no-layer military fortress defense. This period was mainly the King Hailing period of Jin Dynasty, forming a small peak of building cities in Jin Dynasty.

After the Great Wall Military Defense Center moved to Zhongdu Daxing Prefecture from Shangjing Huining Prefecture, the overall planning of the boundary moats changed greatly, and became totally different no matter in distribution or battle line length. Undoubtedly, this forced the defense capability of the Great Wall settlements to promote. Since the length of the military battle line increased by nearly three times, the cooperative engagement capability and left-side and right-side mutualdefense function, and the armed forces and material resources supply of the rear for the battle front.

In such a situation, the Jin military settlements greatly changed, and the linear layout and military fortress hierarchy highlighted. The front border fortress were distinctively divided into two kinds: the small fortress (barrier fortress) attached to moat wall, as the forefront combat unit, did not only send the combat information to the rear in time, but also held off the enemy's attack; the larger border fortress (garrison fortress), located behind the small fortress, presented a several-for-one relationship, namely, several small fortresses for one larger fortress. It was mainly used for providing combat rear support for small fortresses, and stationing a small number of troops and military materials.

In this period, a lot of military fortresses were built and the overall defense capability was strengthened. The fortress cities of different levels were distinctively different in size, and their defense capabilities were also different. The small fortresses attached to the moat were small in perimeter, whose side length generally ranged from $20 \mathrm{~m}$ to $50 \mathrm{~m}$ and the wall body, with a gate, were relatively low; apart from these, there were no other defense installations. The perimeter of the garrison fortress was larger, whose side length was generally around $200 \mathrm{~m}$; there was a gate on the wall; and there were frustums, horse faces and moats, so the defense installations were improved. [1]

\subsection{Planar hierarchical defense period}

The Jin Great Wall Military Settlement defensive system in this period became completely mature, and this period was mainly the period of Emperor Shizong of Jin and Emperor Zhangzhong of Jin. Besides, this period was the peak of building cities in Jin Dynasty. [3]

During this period, a defense pattern with Zhongdu Daxing Prefecture as the defense center and Shangjing Huining Prefecture as the defense sub-center was completely formed. Based on the linear hierarchical defense, the hierarchy of Jin military settlements was more complete and a hierarchical structure from border fortress, to troop stationing city to command fortress was formed. The defense-in-depth capability was greatly strengthened, and the defense comprehensively became planar hierarchical defense from linear hierarchical defense. As a result, the enemies would meet with resistance on the attack route and be pinched them from both sides. Such defense model showed the highest level of the military settlement defense system of Jin Dynasty.

In this period, a lot of new military fortresses were built and many early military fortresses of Jin Great Wall were repaired, so the shapes and structures were relatively confusing, which caused some problems to the study. [5] However, on the whole, the defense capability of the military fortresses was promoted again and the defense installations were strengthened. There were few moat-attached fortresses, and the border fortresses were not built close to the border wall but in a certain distance; besides, the side length became larger and their defense became stronger; defense installations increased, such as frustums, horse faces and moats; and the number of horse faces also increased. Moreover, the defense of troops stationing city and command fortress became more thorough. 
3 HIERARCHICAL CHARACTERISTICS OF JIN GREAT WALL MILITARY SETTLEMENTS

In the Great Wall military settlement defensive system, according to the different administrative functions of officials garrisoning the military fortresses, the fortresses can be divided into three grade: command fortress - troops stationing fortress - border fortress; after detailing, it can be divided into six small grades: route-level command fortress prefecture-level command fortress - key fortress village - common fortress - village - garrison fortress - barrier fortress. (See figure 1)

The grade of cities is usually determined by the grade of officers and soldiers stationing in the cities. According to the statistical data, the grade of military fortresses and the size of cities are consistent. Namely, the higher the grade of a military fortress is, the larger the size of a city is, the more troops there are, and the stricter the defense installations are; and vice versa.

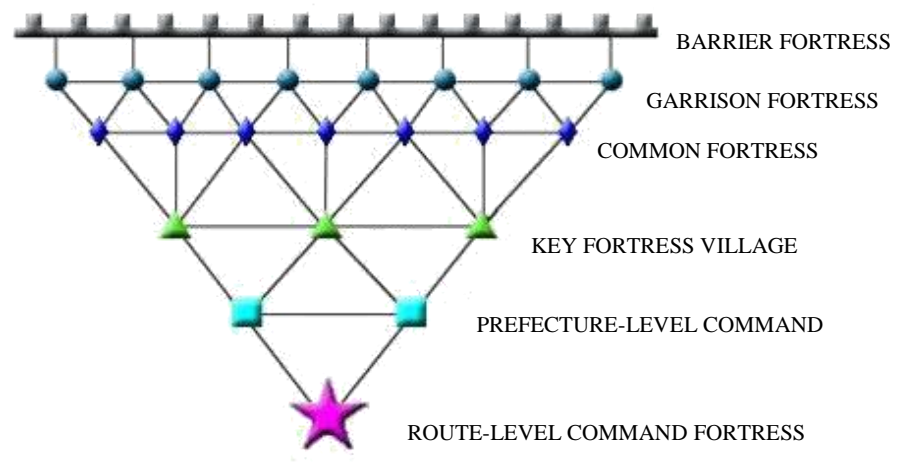

Fig. 1: Hierarchical diagram of military settlements

The administrative function and military function of the command fortresses are equally important, and the command fortresses are divided into routelevel ones and prefecture-level ones. Usually, the cities are large in size, with a perimeter of usually over $4000 \mathrm{~m}$; the prefecture-level command fortresses are stations of tribal troops military governor and deputy amnesty and expedition envoy directly under Amnesty and Expedition Department. And several fortresses are set in every defense area; they are lower-level defense areas and also lowerlevel defense units, administering the subordinate troops stationing fortress villages. The size of cities is only second to that of the station of Amnesty and Expedition Department, with a perimeter ranging from $2500 \mathrm{~m}$ to $4000 \mathrm{~m}$. [2]

The troops stationing fortress villages are under the orders of the command fortresses and they hardly have any administrative function but are mainly used for the military function. They can be divided into key fortress villages and common fortress villages. They are mainly for stationing troops to protect the command fortress city and responsible for offense and-defense issues of the Great Wall sections under their jurisdiction and deploying the garrison task of border moat fortress in their sections. The cities are medium in size, with a perimeter ranging from $1000 \mathrm{~m}$ to $2500 \mathrm{~m}$.

The border fortresses, having military function only, are under the orders of the troops stationing fortress; and they are at the lowest level in the Great Wall military settlement defense system, but the quantity is the largest. They can be used to station a few troops and as battlefronts. They are responsible for watching over and defending the boundary moats and horse faces around them. The leaders stationing there are Mouke, Xiangwen, deputy amnesty and expedition envoy and decurion. [4]The cities are small in size, with a perimeter of less than $1000 \mathrm{~m}$. According to their geographical position and size, they are divided into barrier fortress and garrison fortress.

\section{INTEGRATED CONSERVATION OF JIN GREAT WALL HERITAGE}

The conservation of Jin Great Wall should be considered broadly and narrowly. With integrity as the starting point, not only should the Great Wall body be conserved, but also a large number of military settlements and densely interlaced postal delivery (fire delivery) system should be conserved; not only should Jin Great Wall material tangible cultural heritages be conserved, but also the humanistic environment, natural environment and military culture and other natural and cultural resources on which the Jin Great Wall is based should be conserved. [6]

The integrated conservation principles should be made through the fundamental research; and much attention should be paid to the hierarchies of Jin Great Wall and the conservation range of the hierarchies. For the conservation of hierarchies, the geographical positions of the Great Wall and the military settlements at different levels should be determined; the military traffic routes between the military settlements and between the military settlement and the Great Wall should be made clear, and the military grade and spatial distribution of the cities should be conserved correspondingly. The demarcation of conservation range of different hierarchies is an important precondition and component of the demarcation of integrated conservation range of the Great Wall.

The Great Wall military settlements are featured by large temporal and spatial span, coverage of many fields and huge amount of information and so on. The traditional research method and technical means can not meet the need to study the Great Wall. For the large-scale regional study object, it is necessary to introduce such spatial information technologies as GPS, GIS and RS, establish the spatial database of settlements, integrate the spatial 
and property data of settlements and further explore the technical routes to establish the spatial database of traditional settlements.

\section{REFERENCES}

[1] Xie Dan. Study on Relationship Between Overall Spatial Layout of the Great Wall and Location of Capital of Jin Dynasty. City Planning Review 2014(4):70-73.

[2] Pang Zhiguo. A Survey on Jilin Provincial Border Moat Fortress of Northeastern Linhuang Route in Jin Dynasty. Cultural Relics Edit Committee. 1981(01):84-88. Collection of Reports on Chinese Great Wall Relics. Bei Jin: Cultural Relics Press.
[3] Li Wenxin. 1992. Li Wenxin's Collected Archaeological Works. Liao Ning: Liaoning People's Publishing House.

[4] Cheng Nina. 1986. Essays on History of Jin Dynasty II. Ji Lin: Jilin Literature and History Press.

[5] Cheng Nina. 1999. A Study on the Political System of Jin Dynasty. Ji Lin: Jilin University Press.

[6] Chen Xibo, Han Guanghui. On Development of Zhongdu Route Urban Agglomeration of Jin Dynasty and its Spatial Distribution Characteristics. Journal of Chinese Historical Geography 2008 (01):25-33.

[7] Jin Yingxi. 1985. Ancient Chinese Great Wall as the Military Defensive Line and Cultural Convergence Line, Chiefly edited by Chinese History Association, The 16th International Congress of Historical Sciences: Collection of Chinese Scholars' Papers, 1985: 271-291. Beijing: Zhonghua Book Company. 